\title{
Using multimedia learning modules in a hybrid-online course in electricity and magnetism
}

\author{
Homeyra R. Sadaghiani* \\ California State Polytechnic University, Pomona, California, USA
}

(Received 8 December 2010; published 24 March 2011)

\begin{abstract}
We have been piloting web-based multimedia learning modules (MLMs), developed by the Physics Education Research Group at the University of Illinois at Urbana Champaign (UIUC), as a "prelecture assignment" in several introductory physics courses at California State Polytechnic University at Pomona. In this study, we report the results from a controlled study utilizing modules on electricity and magnetism as a part of a blended hybrid-online course. We asked students in the experimental section to view the MLMs prior to attending the face-to-face class, and to make sure this would not result in additional instructional time, we reduced the weekly class time by one-third. We found that despite reduced class time, student-learning outcomes were not hindered; in fact, the implementation of the UIUC MLMs resulted in a positive effect on student performance on conceptual tests and classroom discussion questions.
\end{abstract}

DOI: 10.1103/PhysRevSTPER.7.010102

\section{INTRODUCTION}

The use of computers in the learning of physics content can be an effective tool. For example, researchers found that students using real-time graphs with a microcomputerbased laboratory significantly improved their kinematics graphing skills and their understanding of the qualitative aspects of motion [1]. Workshop Physics is another excellent example of a program that incorporates computer technology into real experiences [2]. Analyzing the effect of Workshop Physics on student learning showed dramatic improvements in student conceptual learning in the topics of kinematics, dynamics, latent heat, and electricity [3]. Recently, computer simulations have become valuable tools for bridging gaps in students' understanding of concepts $[4,5]$. Increasing capability in multimedia computing and access to the World Wide Web have resulted in increased availability and use as well as research in utilizing multimedia in education. For example, the result of a clinical study conducted by the University of Illinois at Urbana Champaign (UIUC) Physics Education Research (PER) group [6] indicated students using the multimedia learning modules (MLMs) outperform their peers who do reading assignments from a standard textbook [7]. Additionally, a recent study shows that viewing the MLMs better prepares students for introductory physics class [8] and makes the course less difficult in students' perceptions [9].

Hybrid courses are courses in which a portion of the learning activities has been moved online, and time

\footnotetext{
*hrsadaghiani@csupomona.edu

Published by American Physical Society under the terms of the Creative Commons Attribution 3.0 License. Further distribution of this work must maintain attribution to the author(s) and the published article's title, journal citation, and DOI.
}

PACS numbers: 01.40.Fk, 01.40.G-, 01.50.H-, 01.50.Lc

traditionally spent in the classroom is reduced but not eliminated. The goal of hybrid courses is to integrate more effective features of in-class teaching with the potential features of online learning to promote active independent learning, add flexibility to a student's schedule, and reduce class seat time. Using computer-based technologies, instructors use the hybrid model to redesign some lecture or lab content into new online learning activities such as case studies, tutorials, self-testing exercises, simulations, and online group collaborations.

This study investigates the effectiveness of web-based multimedia learning modules as prelectures in teaching introductory calculus-based electricity and magnetism in a hybrid-online format course. In this paper, we first introduce the content of the MLMs and their potential pedagogical advantages. We then describe the details of the controlled study design and compare the data on a test for the experimental and control group to gauge student understanding of the physical concepts. We later evaluate the effectiveness of the MLMs for student preparation for class activities by comparing student responses to identical clicker questions in both sections. In addition, we present some of the student perceptions and feedback regarding the MLMs. We conclude by presenting some implications of the study.

\section{MULTIMEDIA LEARNING MODULES}

It is increasingly difficult for traditional teaching techniques to capture and maintain student interest for a long period of time. Many educators consider multimedia technology as a useful teaching tool that can capture the attention of today's students $[6,10,11]$. Multimedia applications in education can be defined as any learning experience that involves more than one medium for delivery, organization, and presentation of the learning activities. In 
general, these media could include narrations, animations, chalkboards, paper and books, and video and movies. In the past decade, the field of multimedia learning has emerged as a coherent discipline with a great deal of research at its base. Research shows that students can benefit from technology-enhanced multimedia learning supplements that unify concepts and are delivered on demand over the Internet [12-14].

The MLMs used in this study, developed by the UIUC PER group, are combinations of various media within a single computer program streamed online. The MLMs are learning activities designed to introduce the key course concepts through flash animations with synchronous narrations that are typically $12-15 \mathrm{~min}$ long. Figure 1 is a screen shot of the Electric Field MLM [15]. Each module has two or three questions that are embedded into the content itself. Students must answer the questions correctly in order to proceed. Automatic feedback and related prompts guide students in determining the correct answers to these questions. Students view the material as prelectures before attending each face-to-face lecture.

In teaching physics, we depict physical concepts with multiple representations ranging from pure words to equations, graphs, and diagrams. Many students have considerable difficulty not only with creating these representations but also in seeing how they express information and how they are related to each other [16]. The challenge becomes even greater when students do not have real world experiences or mental images of the concepts they face in their introductory college courses, concepts such as flux, electric potentials, electric fields, imaginary Gaussian surfaces, etc. The MLMs not only provide multiple representations of physics phenomena through graphs, animations, movies, and narration, but also create a dynamic and simultaneous visualization of these concepts plus their relationships with one another. These dynamic representations are an important component of learning physics, and

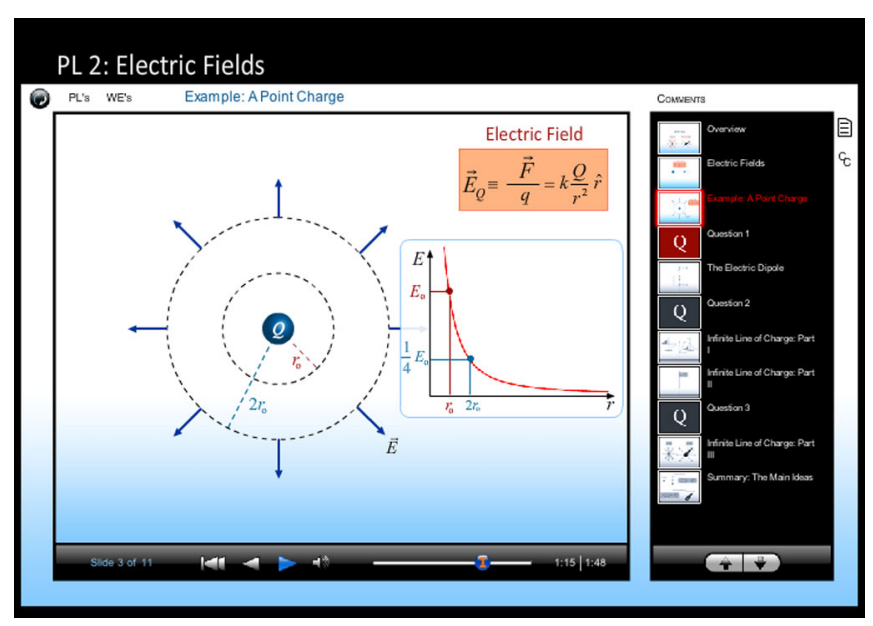

FIG. 1 (color online). Screen shot of the online multimedia prelecture on electric fields. these techniques can contribute to students' understanding of physics concepts by providing mental images to attach to the concepts.

The design of the multimedia learning modules is informed by the findings of physics education research as well as in-depth research on multimedia learning. The multimedia learning modules utilize the findings of research in physics education in its content. For example, many of the embedded questions are carefully selected from the body of research in physics education to address common student difficulties; an immediate feedback to incorrect student responses provides scaffolding for students' thought processes by offering easier guiding questions, and in doing so engages students in the process of active learning. By using animations, the prelectures display multiple representations of the concepts simultaneously to connect words to equations, diagrams, and graphs, which create a common mental image of abstract concepts. Finally, by having students view the material before the face-to-face meeting, instructors can link the class activities and examples to students' previous knowledge that can result in a more robust understanding of the course content.

Each MLM has a play, pause, and fast-forward button, allowing learners to take control of the pace of instruction. Students can view a complex concept or derivation of a principle on one slide as many times as they wish before moving to the next one. They can easily jump back a few slides to remind themselves of a topic previously discussed in one module. Since educational research has demonstrated repeatedly that students learn much more effectively when they themselves are in control $[17,18]$, this flexibly would enhance the usefulness of the MLM.

Multimedia learning modules utilize the finding of research in multimedia learning in their design. Research in multimedia learning suggests that the use of dual learning channels (audio and visual) improves student learning $[19,20]$. Thus, by utilizing both auditory and visual channels to assimilate information, multimedia maximizes students' short-term memory. By focusing on the principles of multimedia [21] and how people learn from words and pictures in computer-based environments, the MLMs coordinate the animations with narration to enhance learning outcomes. Finally, by minimizing unnecessary text or objects, the MLMs demand that students focus on the main ideas.

\section{STUDY DESIGN}

We have implemented the MLMs in several introductory calculus-based courses at California State Polytechnic University at Pomona (Cal Poly Pomona). In this paper, we describe a controlled study that was designed to investigate the effectiveness of the MLMs on student learning and achievement in the context of a hybrid-online course on an introductory electricity and magnetism course. 
It may seem that discussion of hybrid and online courses may not align with the goals of physics education research. Considering some early online course qualities, many might believe that traditional, face-to-face teaching is always better. Some may reluctantly accept some benefits of online courses, justifying them on the basis of distance learning and economical constraints, but even those people see online teaching as a second-best alternative, something to be done by others. Nevertheless, the recent demand and interest in developing online and hybrid courses in both public and private institutions of higher education has intensified in recent years [22]. For the university, the benefits of online and hybrid courses include reduced costs and increased ease of disseminating instruction. For students, these types of courses offer more distance-learning opportunities, convenience, and flexibilities. Especially for the diverse population of students at Cal Poly Pomona, many of whom have day jobs and families to support, taking a course online may be the only option. As an educator and researcher, my goal is to improve student learning by continuously refining both the content and associated pedagogy of the physics courses. To this end, my objective in this project is to collect and analyze data in order to compare the learning and experiences of students in traditional face-to-face physics course with those using the MLMs in a hybrid-online format.

\section{METHODOLOGY}

We started piloting the UIUC online MLM prelectures in Fall 2008 by implementing three modules into an introductory calculus-based electricity and magnetism course (PHY 133) for engineering and physics majors at Cal Poly Pomona. After positive feedback from students, in Spring 2009 we designed a controlled study to investigate the effectiveness of the online prelectures on student learning, achievement, and preparation for class discussions. Students in one section of PHY 133 served as the control group $(N=48)$ while the experimental hybrid-MLM group $(N=34)$ was offered the MLM as online prelecture assignments. Both classes met twice a week. The control class met $75 \mathrm{~min}$ each period while the hybrid-MLM class met for $50 \mathrm{~min}$ and the students in this group were required to view one module before each face-to-face class meeting. Both classes were asked to complete brief online conceptual quizzes (called preflights) based on the topics covered in lectures and the textbook reading assignments. These preflights consisted of a set of just-in-time-teaching (JiTT) [23] multiple-choice questions accompanied by freeresponse questions where students provided reasoning for their multiple-choice answers. The MLMs were available through Blackboard Learning Management System to the students and were linked to the UIUC server. Students received points for viewing the MLMs and completing the preflights as part of their grades. The control group also received points for completing the online preflights

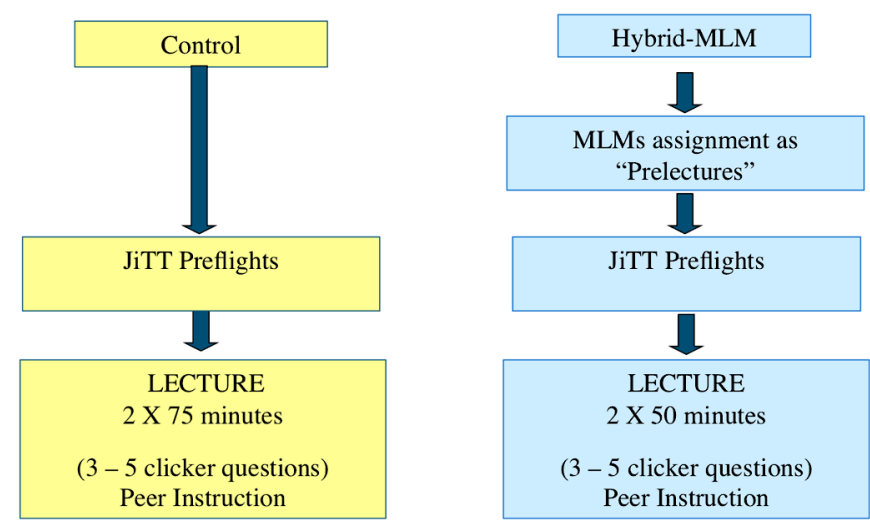

FIG. 2 (color online). A schematic representation of the controlled study design. The students in the MLM group viewed an average of two MLMs per week, a total of 17 during the quarter.

prior to class. Students in the MLM group viewed a total of 17 modules on the topics of the course during the quarter. Figure 2 illustrates the schematic layout of the research study. All the other aspects of the course, including homework assignments, class examples, and exams, were the same; the author was the instructor for both sections.

The two classes were very similar in their background as measured by the survey. For example, the average GPA for the hybrid class was 3.0 compared to 2.9 for the control group, and the percentage of students receiving grades "A," "B," and "C" in their previous physics course (PHY 131, Mechanics) was also comparable.

\section{DATA COLLECTION}

In order to examine the effect of using the MLMs, we collected three primary data streams from both groups: (I) Conceptual Survey of Electricity and Magnetism (CSEM) [24], (II) student responses to identical clicker questions during the lecture, and (III) survey data on usefulness of different course components.

\section{A. Conceptual Survey of Electricity and Magnetism}

The CSEM is a 32-item, multiple-choice instrument used to test understanding of subjects covered in a typical introductory electricity and magnetism course. Using the CSEM, we measured students' conceptual understanding of the topics presented in this course. The CSEM was used as both a pretest (first week of the quarter) and as a post-test (last week of the quarter). In order to compare the results across both sections, we calculated the normalized gain $\langle g\rangle$, which is the ratio of the actual to the maximum possible gain:

$$
\langle g\rangle=\frac{(\text { post-test }- \text { pretest }) \%}{(100-\text { pretest }) \%} .
$$

Students in both groups were supposed to complete the pre- and post-test survey in $30 \mathrm{~min}$. However, this time was 
TABLE I. Pretest and post-test scores (with their relative standard errors) as well as normalized gains on the CSEM.

\begin{tabular}{lccc}
\hline \hline Courses & Pretest & Post-test & $\langle g\rangle$ \\
\hline Hybrid-MLM $(N=29)$ & $24 \% \pm 4 \%$ & $58 \% \pm 4 \%$ & $45 \%$ \\
Control $(N=40)$ & $27 \% \pm 3 \%$ & $54 \% \pm 3 \%$ & $37 \%$ \\
\hline \hline
\end{tabular}

not sufficient for most of our students; therefore, we only included the questions that the majority of the students had completed (1-20). Most of these first 20 questions focus on electricity; thus, the questions regarding magnetism were not included in the analysis of the scores. In addition, only data for students who completed both pre- and post-test surveys were included in the calculation of the gain. The results of the student performance in CSEM are summarized in Table I.

There was no significant difference in pretest results between the hybrid-MLM and the control group. However, the hybrid-MLM group outperformed the control group in the post-test, resulting in $8 \%$ higher normalized gain (45\% vs 37\%). Previous CSEM data for over 5000 students at 30 different schools (see ref. [20]) indicated that typical pretest scores are $31 \%$ for students in calculusbased courses and $25 \%$ for students in algebra-based courses; post-test data only rise to $47 \%$ and $44 \%$, respectively. Since our results do not include all 32 items of the CSEM, a direct comparison is not possible.

\section{B. Clicker questions administered during class}

During class meetings, the instructor frequently posed questions using clickers. These questions were content questions asking for recall of information, conceptual questions seeking evidence of understanding, application questions demanding critical thinking, or synthesis questions in problem-solving formats. Students were encouraged to follow an approach similar to Peer Instruction [25] and talk to their neighbors in class before voting.

For 38 identical clicker questions on topics relevant to lecture instruction and textbook readings, the average percentage of the correct answers in the hybrid-MLM class was $60 \pm 4.0 \%$; for the control group, it was $54 \pm 3.0 \%$. This difference in means leads to a small effect size (ES) of 0.25 , where ES is a statistical concept that measures the strength of the relationship between the two variables and reflects the standardized mean difference by dividing the two population mean differences by the standard deviation of the control group:

$$
\mathrm{ES}=\frac{\bar{\mu}_{1}-\bar{\mu}_{2}}{\sigma} .
$$

The ES of about 0.2 corresponds to a small effect, while 0.5 is considered a medium effect, and 0.8 and greater reflects a large effect size. Although not statistically significant, we are inclined to attribute the slightly better performance of the students in hybrid-MLM group in this study to their

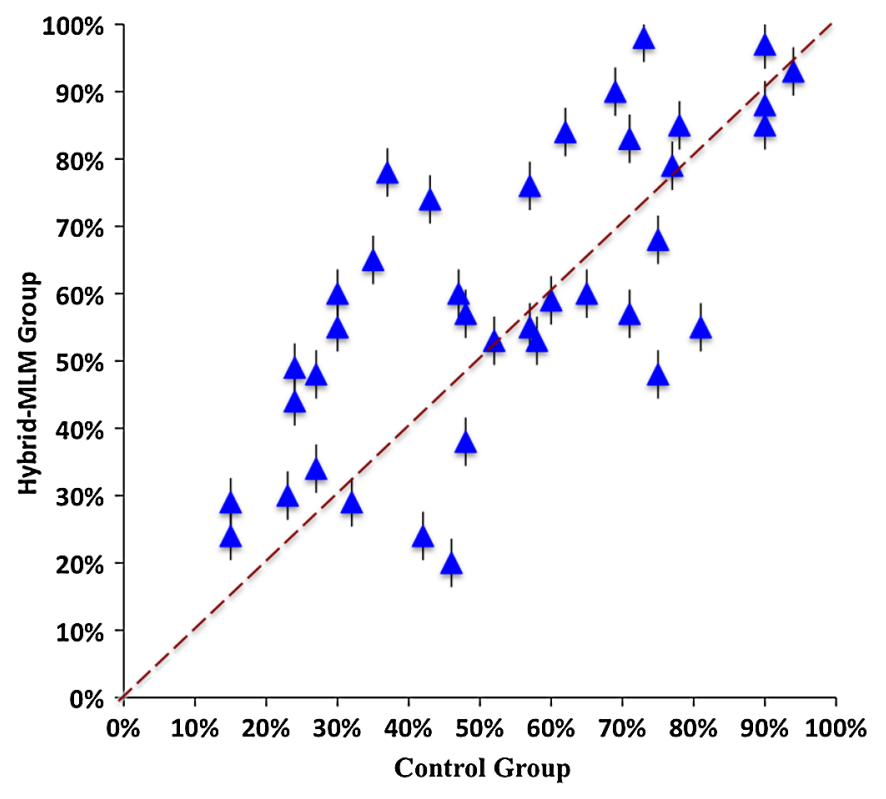

FIG. 3 (color online). Scatter plot of student correct responses to 38 identical clicker questions in control and hybrid-MLM classes. Each point represents one clicker question where the average correct responses for the control group and hybrid-MLM are on the $x$ and $y$ coordinates, respectively. The error bars represent the standard error for each question and the dashed line represents the $x=y$ line.

initial exposure to the content through viewing the MLMs prior to class meeting. A scatter plot of the average scores on each of these 38 questions for students in both groups is presented in Fig. 3. The students in the hybrid-MLM class had a higher percentage average for the correct answers and outperformed the control group in 21 out of the 38 common questions (points above the $x=y$ line.)

\section{Student feedback}

At the end of the quarter we administered a survey to elicit student feedback on the usefulness of different course components in both classes and received specific feedback on student attitudes and experience with the MLMs in the experimental group. The survey questions consisted of three formats: multiple-choice, ranking scales, and openended.

We asked students in both classes to rank the usefulness of different course components to their learning on a scale from 1 to 5 (in which 1 is "not useful at all" and 5 is "most useful"). Student responses from both groups are represented on the bar graph in Fig. 4. The textbook was ranked the lowest in both classes: many students stated that they do not find the textbook useful in their learning $[6,26]$. In addition, students in the hybrid-MLM class gave the prelectures a much higher average ranking than the textbook. The average rankings of the usefulness clickers by students in the hybrid-MLM class were slightly higher than those of the control group, suggesting that viewing the MLMs did 


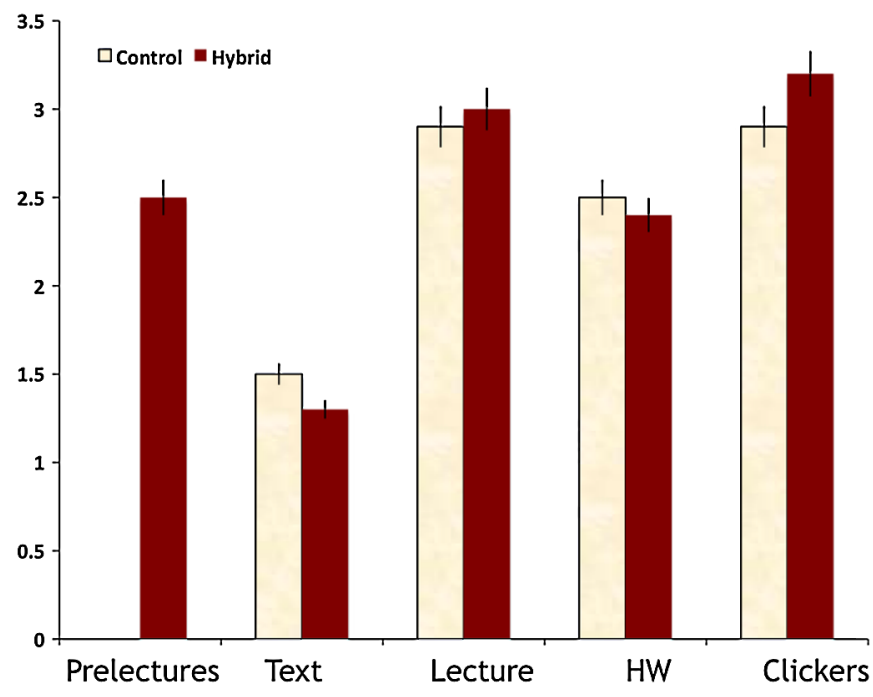

FIG. 4 (color online). Student rankings of the usefulness of the course components for both the control and the hybrid-MLM groups. We used MasteringPhysics online homework.

not diminish their interest in class discussions and peer interaction. In fact, students in the hybrid-MLM class seem to be more engaged with the questions and discussions than the control group, perhaps due to some prior preparation via the MLMs. There were no significant differences in the average rankings of the usefulness of lectures or homework between the two groups.

In regard to students' perceptions of the MLMs, the study found that over $75 \%$ of the students felt the activities were either effective or very effective in helping them learn the physics concepts presented in the prelectures. In addition, the majority of students (90\%) felt the technical issues related to accessing and viewing the MLMs were very easy. About $60 \%$ of the students strongly preferred the hybridMLM format compared to $25 \%$ who strongly preferred pure face-to face format.

On the open-ended survey questions regarding the MLMs, student overall feedback was very positive. Nearly three-fourths of students (72\%) valued the capabilities provided by the Internet and multimedia (flash movies, playback, pause, dynamic diagrams, and the synchronized narrations) and stated that the addition of these course components to the in-class discussion was very effective in helping them learn the physics concepts. For instance, many students indicated that they found the MLMs "very useful in visualizing the concepts" and that they liked the fact that they could view the MLMs "anywhere, anytime," and as "many times" as they wanted. In comparing the MLMs to the textbook, several students preferred the conciseness of the MLMs over the textbook content.

\section{DISCUSSION}

This study investigated the effects of using the MLM prelectures in a hybrid-online introductory college electricity and magnetism course on student learning and attitudes. The study examined student conceptual understanding and preparation for the classroom discussion questions. The study also surveyed students' feedback on the usefulness of different course components and their perception of the effectiveness of the MLM as well as student attitudes towards using the MLMs in a hybrid-online course.

Our data indicate that replacing one-third of the weekly face-to-face class time with the UIUC online MLMs did not have any negative impact on the course. In fact, in the class where the MLMs were utilized, students showed slightly larger gain in CSEM. Also, students who viewed the MLMs had a higher percentage of correct responses for identical clicker questions administered during class. Finally, students found the MLMs useful, interesting, and effective in their learning and rated them higher than the course textbook. It is worth mentioning that the comparison of final exam scores between students in the control and those in hybrid-MLM group showed no significant differences.

The results of this study are encouraging in that the study demonstrates that the UIUC MLMs can provide physics instructors with additional online course material that incorporates findings of physics education research within a user-friendly technology. The findings suggest that the MLMs can positively affect students' learning of the concepts, enhance their class performance, and is accessible from anywhere at anytime. Student attitudes regarding the MLMs were very positive; they enjoyed the flexibility associated with the online course material, felt they were easy to use, and found the presentations and examples to be very effective in helping them learn the material. We attribute these positive impacts to the quality of UIUC content and suspect that using the MLMs in a more standard situation (without reduced face-to-face time) would have produced the same or better results [27].

As educators and researchers we need to seek welldesigned online course materials that can increase student engagement with the course content outside the classroom and perhaps result in measurable learning outcomes. Although some might reasonably argue that online course components cannot compare to or replace face-to-face instruction, the development of technology, amplified use of computers, economical constraints, growing body of students, social factors, and increased need for distancelearning opportunities will demand more and more online courses in the near future. Online enrollments have grown much faster than overall higher-education enrollments over the past few years. Indeed, during the period from 2002 to 2007, enrollment in online courses grew 19.7\%, compared to a $1.5 \%$ growth in the overall college-student population [28]. According to Washington Business Journal, the number of students taking online college classes jumped by nearly $1 \times 10^{6}$ last year, a $21 \%$ increase at a time when the 
higher-education population increased just 2\%. These numbers suggest tremendous interest in online teaching and learning and the possible increase on the number of online courses that will be offered in the near future. Student and course data from the 2010 PeopleSoft database at Cal Poly Pomona show that 53 online and 67 hybrid courses were attended by 5790 students in Fall 2010 alone and 18746 students in total were enrolled in those online or hybrid courses in the year 2010. The number of faculty with online or hybrid courses has increased by $209 \%$ between the Fall 2006 and 2009 quarters, and the total number of student enrollments in such courses increased by $33 \%$.

In summary, the growing capability of dynamic multimedia delivery modes makes the Internet a much more appealing resource to our students than static textbooks. Thus, discipline-based education researchers should consider systematic investigation of this medium and its potential strengths and weaknesses in promoting student learning. For instance, research could investigate whether or not converting a previously successful curriculum into an online or hybrid-online delivery format could be an effective pedagogy, what criteria and strategies can provide and maintain an effective online learning environment, or if online multimedia course delivery could increase student interest in learning physics in $\mathrm{K}-12$ education. Additional investigations and careful measurements of student learning are needed to further study the effect of multimedia and innovative online pedagogies in learning physics.

\section{ACKNOWLEDGMENTS}

The author would like to acknowledge the support of the Physics Education Research Group at the University of Illinois at Urbana Champaign for the implementation of the modules. In particular, I would like to thank Professor Tim Stelzer for his thoughtful contributions in this study. I would also like to thank Professor MacKenzie Stetzer for his helpful suggestions in preparing this manuscript.
[1] R. K. Thornton, Tools for scientific thinking: Learning physical concepts with real-time laboratory measurement tools, in Proceedings of the Conference on Computers in Physics Instruction, edited by E. F. Redish and J. Risley (Addison-Wesley, Reading, MA, 1990), pp. 177-188; R. K. Thornton and D. R. Sokoloff, Learning motion concepts using real-time microcomputer-based laboratory tools, Am. J. Phys. 58, 858 (1990).

[2] P. Laws, Workshop Physics Activity Guide (Wiley, New York, 1997).

[3] P. Laws, Calculus-based physics without lectures, Phys. Today 44, No. 12, 24 (1991).

[4] C. Wieman, K. Perkins, and W. Adams, Oersted Medal Lecture 2007: Interactive simulations for teaching physics: What works, what doesn't, and why, Am. J. Phys. 76, 393 (2008).

[5] N. Finkelstein et al., When learning about the real world is better done virtually: A study of substituting computer simulations for laboratory equipment, Phys. Rev. ST Phys. Educ. Res. 1, 010103 (2005).

[6] T. Stelzer, G. Gladding, J. Mestre, and D. T. Brooks, Comparing the efficacy of multimedia modules with traditional textbooks for learning introductory physics content, Am. J. Phys. 77, 184 (2009).

[7] P. Tipler and G. Mosca, Physics for Scientists and Engineers (Freeman, New York, 2008), 6th ed.

[8] Z. Chen, T. Stelzer, and G. Gladding, Using multimedia modules to better prepare students for introductory physics lecture, Phys. Rev. ST Phys. Educ. Res. 6, 108 (2010).

[9] T. Stelzer et al. Impact of multimedia learning modules on an introductory course on electricity and magnetism Am. J. Phys. 78, 755 (2010).
[10] R. Mayer, Multimedia learning: Are we asking the right questions? Educ. Psychol. 32, 1 (1997).

[11] S. Mousavi, R. Low, and J. Sweller, Reducing cognitive load by mixing auditory and visual presentation modes. J. Educ. Psychol. 87, 319 (1995).

[12] Hypermedia Learning Environments: Instructional Design and Integration, edited by Piet A. M. Kommers, R. Scott Grabinger, and JoannaC. Dunlap (Lawrence Erlbaum Assoc., Inc., Mahwah, NJ, 1996).

[13] R. Mayer, The Cambridge Handbook of Multimedia Learning (Cambridge University Press, Cambridge, England, 2005).

[14] R. Colvin Clark and R. Mayer, e-Learning and the Science of Instruction: Proven Guidelines for Consumers and Designers of Multimedia Learning (Wiley, New York, 2008).

[15] Full MLM modules can be viewed at https://online-s.physics.uiuc.edu/courses/phys212/gtm/ No_Login/page.html.

[16] A. Van Heuvelen and X. Zou, Multiple representations of work-energy processes, Am. J. Phys. 69, 184, 2001.

[17] S. McKagan, W. Handley, K. Perkins, and C. Wieman, A research-based curriculum for teaching the photoelectric effect, Am. J. Phys. 77, 87 (2009).

[18] C. Keller, N. Finkelstein, K. Perkins, and S. Pollock, Assessing the effectiveness of computer simulation in introductory undergraduate environments, AIP Conf. Proc. 883, 121 (2007).

[19] A. Baddeley et al., Working memory, Science 255, 556 (1992).

[20] J. Sweller, Cognitive load theory, learning difficulty, and instructional design, Learn. Instr. 4, 295 (1994). 
[21] R. Moreno et al., Cognitive principles of multimedia learning: The role of modality and contiguity, J. Educ. Psychol. 91, 358 (1999); R. E. Mayer, Multimedia Learning (Cambridge University Press, Cambridge, England, 2009).

[22] A. Picciano and J. Seaman, K-12 online learning: A survey of U.S. school district administrators, http:// www.sloan-c.org/publications/survey/K-12_06.asp.

[23] G. Novak, E. Patterson, A. Gavrin, and W. Christian, JustIn-Time-Teaching (Prentice Hall, Upper Saddle River, NJ, 1999).

[24] D. Maloney, T. O'Kuma, C. Hieggelke, and A. Van Heuvelen, Surveying students' conceptual knowledge of electricity and magnetism, Am. J. Phys. 69, S12 (2001).

[25] E. Mazur, Peer Instruction: A User's Manual (PrenticeHall, Englewood Cliffs, NJ, 1997); E. Mazur et al., Peer instruction Am. J. Phys. 67, 359 (1999); C. Crouch and E. Mazur, Peer instruction: Ten years of experience and results, Am. J. Phys. 69, 970 (2001).

[26] K. Cummings, T. French, and P. Cooney, Student textbook use in introductory physics, in Proceedings of the Physics Education Research Conference, Boise, ID, 2002, edited by S. Franklin, J. Marx, and K. Cummings (PERC, New York, 2002).

[27] A similar control study on the modules of Mechanics shows that the addition of the UIUC MLMs with equal face-to-face class time results in a higher average score on the common exam for the MLM group (to be published).

[28] Washington Business Journal, http://washingtonexaminer .com/education/2010/11/online-college-classes-gainingpopularity 